\title{
EDITORIAL
}

\section{Van Gogh}

It is always fun to speculate on the psychopathology of Prime People, the prurience of the private life behind the public face; how much did it contribute to their success or failure. Their morbid pathology can be just as intriguing, and then at least we have firmer grounds on which to base our surmise; especially is this true if we are dealing with underlying factors which can be exactly calibrated, like optics and colour where changes in the artist's rendering can be directly related to a particular experience or pathological state.

Of all the artists whose work has been subjected to such crude analyses, Van Gogh leads the field, both in terms of the number of articles published and the diversity of the attributions. He is also close enough to our time to allow fairly accurate accounts of his maladies and therapies; and, as the most expensive artist in the bona-fide art market and the hottest property in the under-world, he has become a particularly appealing target for a host of enthusiasts with their wayward theories, and to whom the pathos and drama of his last years lend an added fascination.

In the following account, Arnold and Loftus restrict their survey to the various organic explanations of Van Gogh's preference for yellow, and with their magisterial conclusions few will disagree. For it is only when our conjecture abandon the solid shores of science, and float blithely through increasingly speculative waters that the real trouble begins: as Sir Thomas Browne nicely had it, "What song the sirens sang and such-like questions . . . . admit a wide solution".

PATrick Trevor-Roper

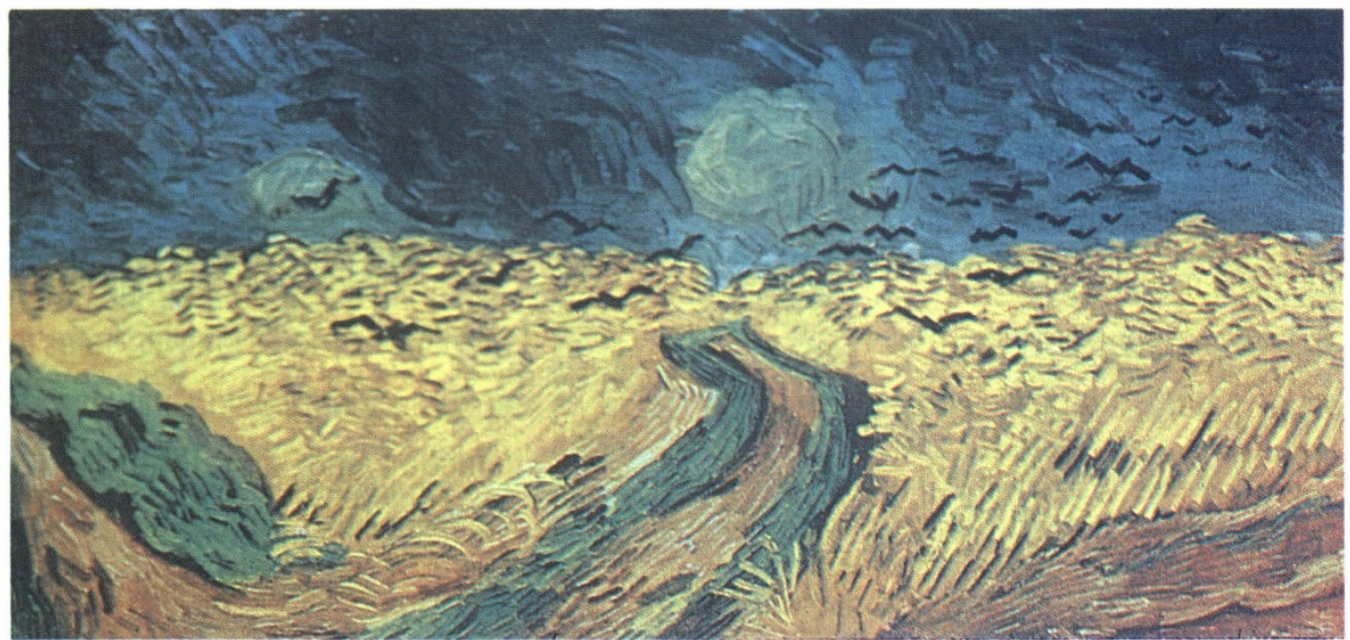

